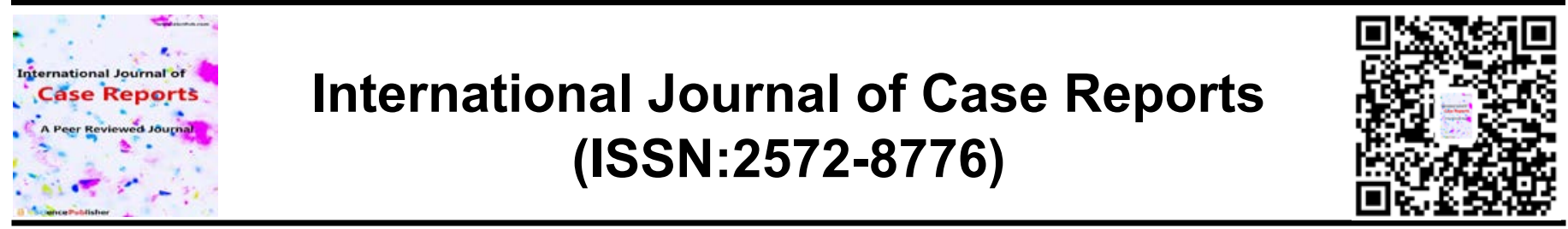

\title{
Retained Penile Ring: Case Reports
}

\section{Odusanya Benjamin Olasunkanmi ${ }^{1}$, Omisanjo Olufunmilade Akinfolarin ${ }^{2}$, Salami Olayinka Abdurraheem $^{3}$, Saliu Abdulwaid Niran ${ }^{4}$}

${ }^{1}$ Consultant urologist, Department of Surgery, General Hospital, Marina, Lagos; ${ }^{2}$ Consultant urologist, Department of Surgery, College of Medicine, Lagos State University Teaching Hospital; ${ }^{3}$ Consultant Orthopaedic surgeon, Department of Orthopaedics, General Hospital, Marina, Lagos; ${ }^{4}$ Consultant urologist, Department of Surgery, General Hospital, Marina, Lagos.

\section{ABSTRACT}

Background: Penile constriction rings have been used to prolong erection with vacuum devices in the treatment of erectile dysfunction. Some have also employed it for recreational purposes with the attendant risks of penile edema, strangulation and necrosis. We present two cases of entrapped phallus by penile rings. Case reports: 16 years old with pain and swelling of the phallus of 12 hours duration. This started after placement of a phallic ring to purportedly prolong erection which he was later unable to remove the ring despite several attempts and developed progressive swelling and pain in the phallus. He was also unable to pass urine. Examination revealed a circumcised phallus that was detumescent but grossly edematous, tender with shiny skin. Initial simple manoeuvres in the casualty proved abortive and ring had to be cut with an orthopaedic instrument. He was subsequently able to void without difficulty or any haematuria. 47 year old Asian male with a 12 hour history of penile pain and swelling following entrapment of a penile ring he had inserted for sexual gratification about 24 hours before presentation. There was a history of haematuria. The removal of the penile ring was achieved with a combination of cold compress squeeze, corporal aspiration and lubrication under general anaesthesia. Conclusion: Successful management of retained penile ring depends on early presentation by the patient to avoid adverse outcomes. It may require instruments not normally found in the urologist armamentarium.
Keywords: penile ring, penile constriction devices, penile incarceration, penile foreign bodies

*Correspondence to Author: Odusanya Benjamin Olasunkanmi Consultant urologist, Department of Surgery, General Hospital, Marina, Lagos.

How to cite this article:

Odusanya Benjamin Olasunkanmi, Omisanjo Olufunmilade Akinfolarin, Salami Olayinka Abdurraheem, Saliu Abdulwaid Niran. Retained Penile Ring: Case Reports. International Journal of Case Reports, $20204: 116$

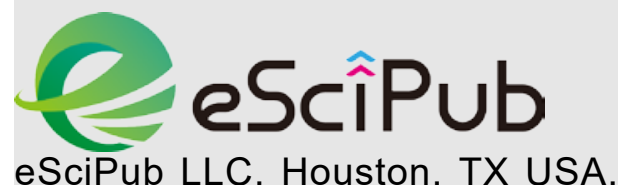
SciPub LLC, Houston, TX USA Website: http://escipub.com/ 


\section{Introduction}

Penile constriction rings have been used therapeutically to prolong erection when using vacuum devices. However, some have employed its use recreationally with the risk of penile edema and strangulation. The management of such rings require removal in a timely manner to avoid attendant complications. There are various methods recommended to removal of such rings with varying success rate. These include string method, aspiration decompression and cutting the ring. A progression from non- invasive to a more invasive technique is usually recommended. ${ }^{1-4}$

We present two cases of entrapped phallus by penile rings.

\section{Case report 1:}

16 years old with pain and swelling of the phallus of 12 hours duration. This started after placement of a phallic ring to purportedly prolong erection. He was later unable to remove the ring despite several attempts and developed progressive swelling and pain in the phallus. He was also unable to pass urine. Examination revealed a circumcised phallus that was detumescent but grossly edematous, tender with shiny skin. The phallus appears viable with a tight ring at the base of the phallus. Initial simple manoeuvres in the casualty proved abortive and ring had to be cut with the aid of an orthopaedic instrument. He was subsequently able to void without difficulty or any haematuria. He was advised on use of cold compress on the phallus. He was also given silver sulphadiazine cream for some minor abrasions on the phallus. The patient however promptly discharged himself from the casualty and was not seen at follow up in clinic.

\section{Case report 2:}

47 year old Asian male with a 12 hour history of penile pain and swelling following entrapment of a penile ring he had inserted for sexual gratification about 24 hours before presentation.

There was a history of haematuria. There was no history of a psychiatric illness or any medical comorbidity.

On clinical examination, he was stable with normal vital signs.

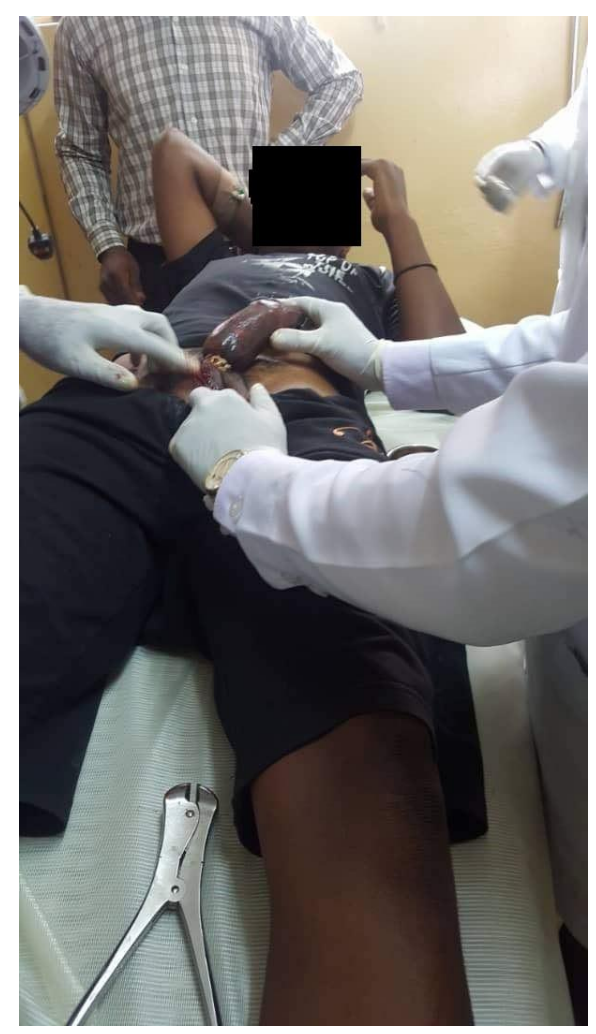

Case 1 before removal

IJCR: https://escipub.com/international-journal-of-case-reports/ 


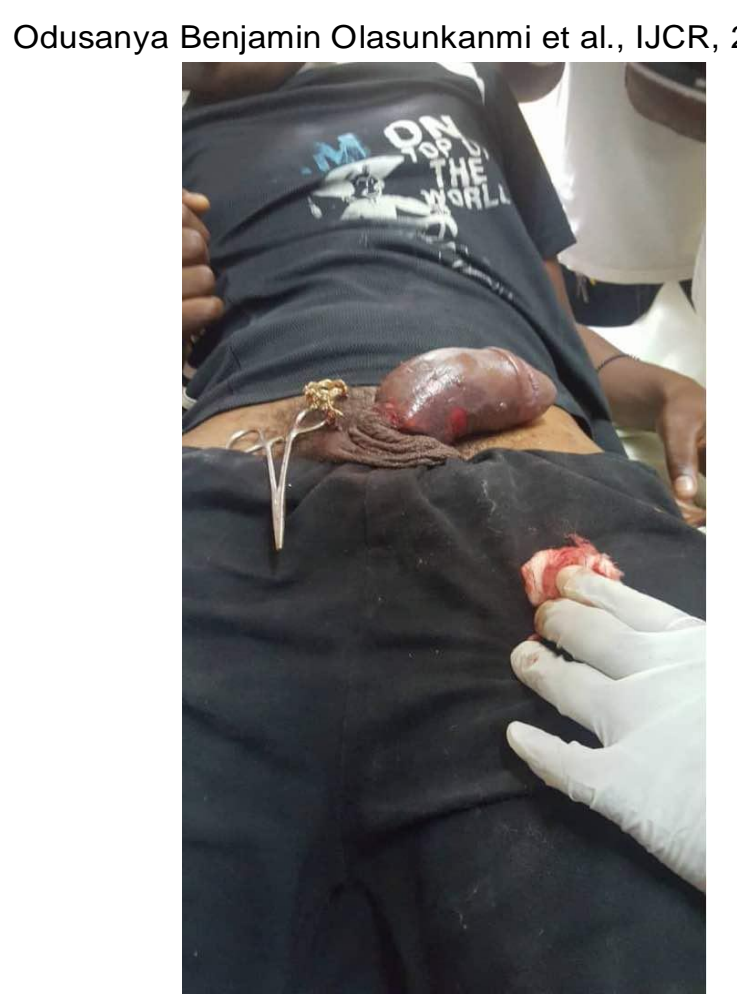

\section{Case1 penile edema after removal}

He had a metallic ring at the base of the penis with an area of constriction. The part of the penis distal to the constricting ring was oedematous and hyperaemic with some patches appearing dusky. The penile sensation was intact.

A diagnosis of a constricting penile injury was made

The removal of the penile ring was achieved with a combination of cold compress squeeze, corporal aspiration and lubrication under general anaesthesia.

There was an area of desquamation of the skin over the constricted penis following the removal of the ring. This area was dressed daily and had healed by the time of his follow up visit 2 weeks later.

He had a urethral catheter passed because of the suspected associated urethral injury. This was removed 2 weeks after the injury and he voided with a good urinary stream.

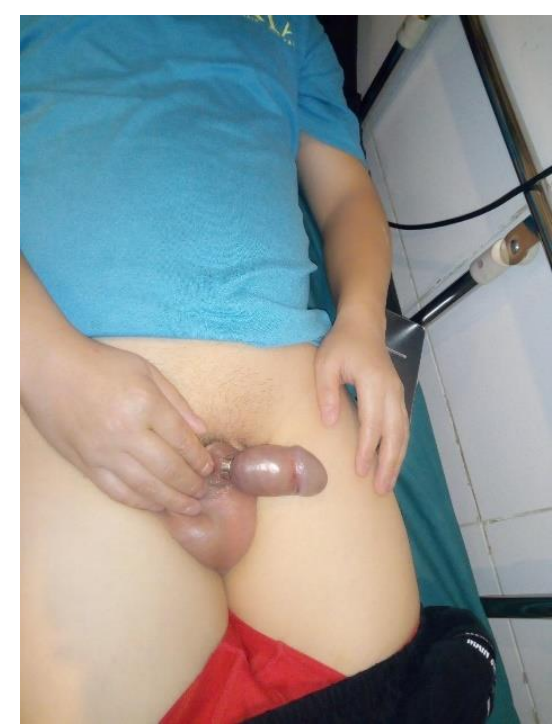

Case 2 Before removal 


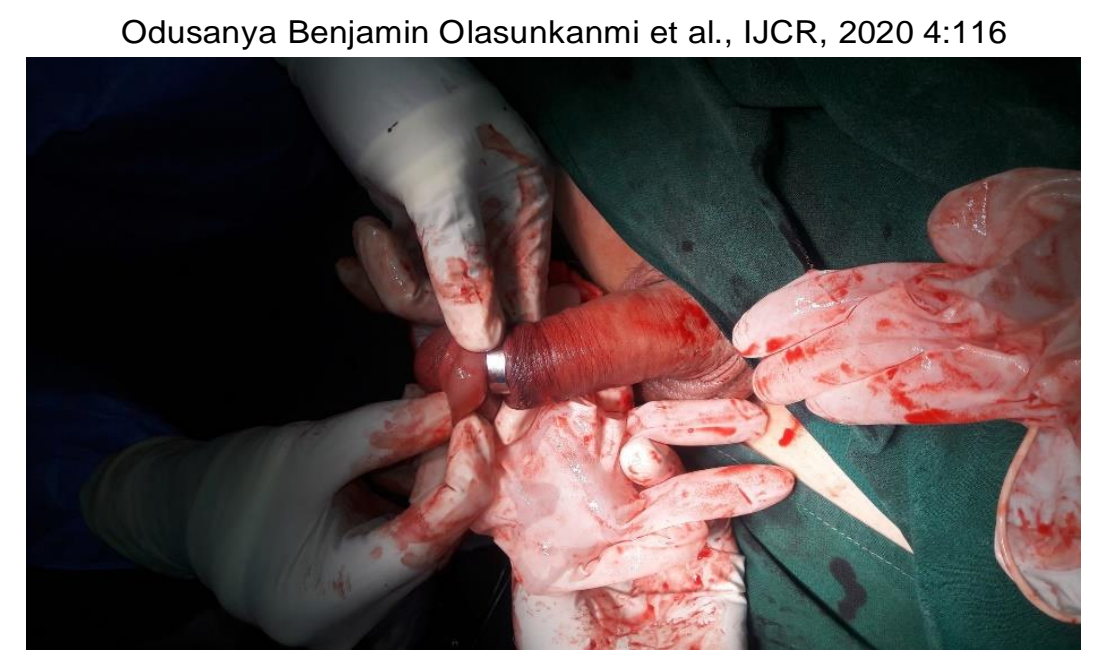

\section{Case 2 during removal}

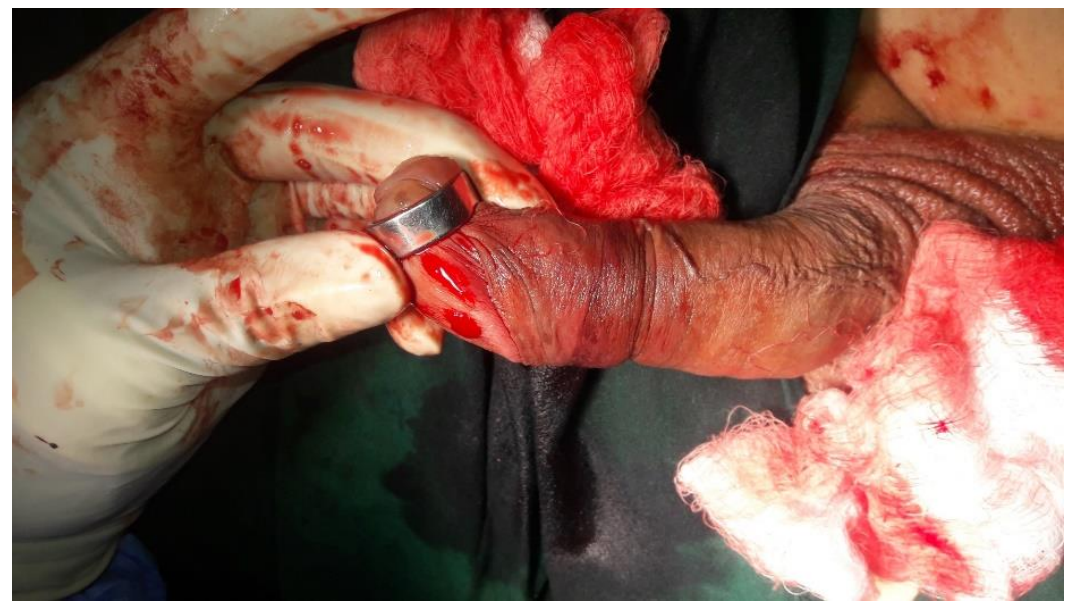

Case 2 final removal

\section{Discussion}

Penile rings have been used to prolong erection but it is associated with the risk of entrapment of the penis and strangulation if left for a prolonged period. Since the description of the first case in 1755, over 60 cases have been described in literature. ${ }^{5}$ This entrapment of the phallus usually present in an emergency setting and many physicians are not familiar with its management. Various objects have been described causing penile entrapment. These include metal rings, plastic bottles, rubber bands, strings and hair. 4, 6,7 These objects are inserted with various intentions ranging from treatment of erectile dysfunction, autoerotic intention, psychiatric disorder and sexual violence. $^{8}$

Different types of injuries can be produced by a metal ring through a combination of vascular and mechanical means. Initially, there is obstruction to lymphatic and venous drainage which leads to increase in hydrostatic pressure and tissue edema. This may eventually lead to arterial obstruction or venous gangrene. Moreover, urethral injury can also occur with either stricture or fistula formation. Bhat el al have classified from grade I to $\mathrm{V}$, ranging from edema of the penis to gangrene and complete amputation of the penis. ${ }^{9}$ The patient in the first case had a grade II injury which included marked swelling of the phallus and some injury to the skin but no evidence of urethral injury whereas the second case had a Bhat grade III injury with some evidence of urethral injury. Both patients have a low grade injury according to Silberstein classification. According to Silberstein et al, low grade injuries include penile edema, skin ulceration, penile anesthesia with no urethral fistula while high grade injuries are those likely to require surgical intervention. ${ }^{10}$ In a recent case series, Bhat 
grade I occurred in $55.5 \%$ and grade $V$ in 11.1 $\%{ }^{8}$

Various methods of anesthesia has been described by different authors. Some have employed penile blocks while others used general anaesthesia. ${ }^{2,3,8}$ In our patients we utilised sedation with benzodiazepine and opioid in the first patient and the second patient had general anaesthesia.

There is no standard protocol for removal and each case is individualised. Techniques which have been described in literature include lubricating the phallus and attempt to manually remove the object, the string technique, corporal aspiration and the use of mechanical devices such as electric drill, hack saw. ${ }^{4,} 11$ Indeed, penile degloving may be performed if these techniques fail. ${ }^{12}$ Cutting the metal ring is a common solution after initial failed attempt of more conservative measures. El Salam et al used bone cutters to divide the ring while Omisanjo et al invited the fire service. ${ }^{3,4}$ In our patients, the second case required simple manoeuvres such as corporal aspiration and manual compression but in the first patient wire cutter provided by the orthopaedic surgeons was utilised to successfully remove the ring.

We aim to highlight increasing number of reports of penile constriction injuries and it is becoming increasingly important that the urologist should be familiar with its management.

\section{Conclusion}

Constricting penile ring is an uncommon emergency which the urologist may encounter. A good outcome depends on early presentation and prompt removal. Instruments not normally found in the urologist armamentarium may be required.

\section{References}

1. Singh I, Joshi MK, Jaura MS. Strangulation of penis by a ball bearing device. The Journal of Sexual Medicine. 2010;7(11):3793-7.

2. Agu TC, Obiechina N. Post coital penile ring entrapment: A report of a non-surgical extrication method. International Journal of Surgery Case Reports. 2016;18:15-7.

3. El Salam A, Ahmed M, Gamal A, Elenany H. Bone cutting forceps: a safe approach for saving strangulated penis. Case Reports in Medicine. 2016;2016.

4. Omisanjo OA, Ojewuyi $O$, Abolarinwa A, Akinola $\mathrm{O}$, Omorinde $\mathrm{M}$, Oshodi $\mathrm{O}$, et al. The fire service for the removal of a metallic penile constricting device: a ready help when all else fail. Case Reports in Urology. 2018;2018.

5. Ivanovski O, Stankov O, Kuzmanoski M, Saidi S, Banev S, Filipovski V, et al. Penile strangulation: two case reports and review of the literature. The Journal of Sexual Medicine. 2007;4(6):1775-80.

6. Okeke LI. Thread embedded into penile tissue over time as an unusual hair thread tourniquet injury to the penis: a case report. Journal of Medical Case Reports. 2008;2(1):230.

7. Lingaraju N, Arunkumar U, Dundappa S, Sali S. Penile strangulation by a hard plastic bottle neck: a case report. Journal of Evolution of Medical and Dental Sciences. 2013;2(19):3335-40.

8. Koifman L, Hampl D, Silva MI, Pessoa PGA, Ornellas AA, Barros R. Treatment Options and Outcomes of Penile Constriction Devices. International Braz J Urol. 2019;45(2):384-91.

9. Bhat $A L$, Kumar A, Mathur SC, Gangwal KC. Penile strangulation. British journal of urology. 1991;68(6):618-21. Epub 1991/12/01.

10. Silberstein J, Grabowski J, Lakin C, Goldstein I. Penile constriction devices: case report, review of the literature, and recommendations for extrication. The Journal of Sexual Medicine. 2008;5(7):1747-57.

11. Noh J, Kang TW, Heo T, Kwon DD, Park K, Ryu $\mathrm{SB}$. Penile strangulation treated with the modified string method. Urology. 2004;64(3):591.

12. Olajide AO, Eziyi AK, Olajide FO, Beyioku BK. Novel surgical extrication of penile constricting metal ring: A case report. International Journal of Case Reports and Images. 2013;4(9):511-4. 